\title{
FEATURES OF THE INTERCONNECTION OF TRADITIONAL RISK FACTORS AND IL-10 WITH THE ACTIVITY OF THE INFLAMMATORY PROCESS AND ATHEROSCLEROSIS DEVELOPMENT IN PATIENTS WITH PSORIATIC ARTHRITIS
}

DOI: 10.36740/WLek202005114

\author{
Liudmyla V. Khimion, Alina V. Boiko \\ SHUPYK NATIONAL MEDICAL ACADEMY OF POSTGRADUATE EDUCATION, KYIV, UKRAINE
}

\begin{abstract}
The aim: To determine the features of atherosclerotic process, cardiovascular risk in patients with PsA.

Materials and methods: The study included 42 patients with PsA who did not have atherosclerotic CVD, diabetes, chronic kidney disease and other serious diseases, did not take statins, the comparingl group consisted of 20 patients with psoriasis (PS) and 20 practically healthy individuals who had no signs of rheumatic, infectious and other inflammatory diseases were screened.

Results: It was revealed that in patients with PsA, the severity of the atherosclerotic process is more compared with patients with PS (the RF profiles were the same). The highest levels of C-reactive protein, fibrinogen, uric acid, intima-media complex thickness, atherosclerotic plaque frequency were found in patients in the PsA group, which may indicate a pathogenetic association of additional RF with the development of a more common atherosclerotic process.

Conclusions: In the development of the atherosclerotic process in patients with PSA, the pro-traditional risk factors play an important role as the immune-inflammatory factors (CRP, IL-10) and additional risk factors (uric acid).
\end{abstract}

KEY WORDS: psoriatic arthritis, psoriasis, atherosclerosis, C-reactive protein, IL-10

Wiad Lek. 2020;73(5):914-919

\section{INTRODUCTION}

Psoriatic arthritis (PsA) is an inflammatory disease of the joints, enthesis and spine, associated with psoriasis [1]. Data on the frequency ofPsA vary widely and make up $0.04-3 \%[2,3,4]$. Most often, the disease begins at the age of 20 to 50 years. The incidence in men and women is the same $[1,12,5]$. The prevalence of PsA among patients with psoriasis (PS) is $5.4-34 \%$ or more $[12,6,7,8]$. In turn, the population prevalence of PS in the vast majority of studies is estimated at an average of $0,5-5 \%$ with significant fluctuations depending on the climatic-geographical region $[9,7,10]$.

It has been established that up to $50 \%$ of deaths among patients with PsA are due to atherosclerosis-dependent CVD. Thus, according to the data of the meta-analysis of data [11], in $55 \%$ of patients with PsA there was an increased risk of developing CVD in this group of patients in relation to the population as a whole, whereas the overall CVD in patients with arthritis was $45 \%$ higher than the average population rate, in particular, the risk of developing myocardial infarction (MI) was higher by $68 \%$, cerebrovascular disease $-22 \%$, and heart failure $31 \%$ [9-10]. Most authors believe that this is due to the presence of atherogenic dyslipidemia (DLP) and systemic inflammation in patients with PsA.
Attention is drawn to the presence of association of cardiovascular catastrophes with an increase in serum sickness of many mediators, which are traditionally used to assess the activity of the inflammatory process, primarily C-reactive protein (CRP) [13]. Even a slight increase in CRP concentrations in a few months and years, reflecting the activity of the inflammatory process characteristic of the PS and PsA, may be a RF for subclinical inflammation in the vascular wall associated with the atherosclerotic process. In this regard, the determination of the level of CRP with the help of a highly sensitive method (the socalled luch-CRP) allows to specify the risk of development, recurrence and progression of vascular complications of atherosclerosis $[13,14]$.

In addition to CRP, the role of uric acid (UA) as an unconventional RF for CVD and its complications is studied at the present stage. It is stipulated that among patients with PS from 19 to $30 \%$ there is hyperuricemia, the level of which depends on the wounds of the area affected by the skin and. Titov V. N. and colleagues. (2013) have shown that in subjects with low and average risk on the SCORE scale, the concentration of uric acid (UA) in serum is associated with an average correlation with lipid profiles, regardless of the presence or absence of a metabolic syndrome, with the relationship of the UA content with 
triglycerides (TG) (positive) and with total cholesterol of high density lipoprotein (TC HDL) (negative) was detected in all studied groups $[11,15]$.

In the general population, the frequency of asymptomatic elevation of the UA is $5-7 \%$, according to other data - up to $12-25 \%$. Important clinical associations of hyperuricemia are DLP, hypertension, obesity, diabetes mellitus, gallstone disease and nephrolithiasis. Asymptomatic hyperuricemia is detected in $25 \%$ of patients with hypertension, including $75 \%$ of patients with severe hypertension (SHEP, 2000) [16]. Taking into account the «traditional» RF of CVD, obesity and metabolic syndrome, the researchers found that the level of UA 6.8-11.1 mg / dl (more than $400 \mu \mathrm{mol}$ / 1) increased 3.29 times the probability of a high level of TC and 1.52 times - an increased amount of CRP in serum [18]. The elevated UA stimulates the activation of RAAS, enhances endothelial dysfunction and provokes hypertension. In a large meta-analysis based on 18 studies, which included 55607 subjects with an average follow-up period of up to 6 years, it was found that the presence of asymptomatic hyperuricemia increases the risk of hypertension by $40 \%$ (RR $1.41 ; 95 \%$ CI: $1.23-1,58$ ) [17].

In the ERA study, an increased concentration of IL-10 was associated with an increased risk of cardiovascular complications in the future in postmenopausal women with established coronary atherosclerosis [19].

In a study in mice with apolipoprotein deficiency and IL-10, it was found that IL-10 deficiency led to LDL cholesterol, whereas LDL cholesterol. IL-10 deficiency plays a detrimental role in atherosclerosis. The early phase of development of the injury was increased, and proteolytic and procoagulant activity was increased. These data show that IL-10 can reduce atherogenesis and improve plaque stability [20].

A. MaLarstig, P. Eriksson, found that IL-10 reflects a pro-inflammatory state in patients with acute coronary syndrome, and it was therefore confirmed that IL-10 is as effective a biomarker for predicting the risk of future cardiovascular events as other markers systemic inflammation[21].

Results of the study Ch. Heeschen, St. Dimmeler demonstrates that increased serum levels of the anti-inflammatory cytokine IL-10 are associated with a significantly better outcome in patients with acute coronary syndrome. The prognostic value of serum IL-10 was independent of elevated troponin levels, reflecting the acute risk of thrombotic complications during acute coronary syndrome. Thus, reduced serum IL-10 levels are not only a marker of plaque instability that contributes to the development of acute coronary syndrome, but more importantly, a poor prognosis even after the occurrence of acute coronary syndrome caused by plaque instability. In addition, the beneficial effects of elevated serum IL-10 levels were limited to patients with elevated CRP, indicating an increased systemic inflammatory response. These data further support the notion that the balance between pro-inflammatory and anti-inflammatory cytokines is the major determinant of the prediction of fatal CVD risk [22].
In modern literature, there is a rather large number of studies devoted to the search for additional RFs of CVD, the definitions of which may improve the assessment and prognosis in patients with PsA with different levels of cardiovascular risk. However, until now, there is no clear answer to many of the key issues that could significantly improve the effectiveness of prevention programs and significantly reduce the high mortality and morbidity rates of CVD in patients with PsA.

\section{THE AIM}

The aim was to determine the features of atherosclerotic process, cardiovascular risk in patients with PsA.

\section{MATERIALS AND METHODS}

The study included 42 patients with PsA who did not have atherosclerotic CVD, diabetes mellitus, chronic kidney disease, and others. severe illness, did not take statins. As a comparison group, 20 people from PS were compared, compared by age and sex. As a control group, 20 practically healthy individuals who had no signs of rheumatic, infectious and other inflammatory diseases were screened. The selection of the control group was done according to the gender and age of the examined patients. The selected patients, at the time of inclusion in the study, had no hypertension and did not take anti-hypertensive medications. All patients were provided with a complex of clinical and instrumental and laboratory examinations, a survey. Anthropometry, blood pressure measurements, questionnaires for the detection of bad habits (smoking, alcohol abuse), anthropometry were used to detect RF, and in order to assess the presence of depression and / or anxiety disorders, patients used the Hospital Alert and Depression Scale (HADS), which was designed to initially detect anxiety and depression in patients (screening) in general medical practice. The burden of heredity was determined by the presence of an atherosclerotic disease or a major RF (high blood pressure, diabetes, and DLP) in relatives of the first-line patient (mother or father) who manifested before the age of 55 in men and women up to the age of 65 years. The PASI (Psoriasis Area Severity Index) calculator was used to assess the degree of skin lesions. All patients with PsA determined the Disease Activity Score (DAS28) index for CRP, and was assessed at an average level of two years. The Alcohol Use Disorder (AUDIT) questionnaire was used for determining the risk group and the number of people who use the health-hazardous amount of alcohol. Identification Test, developed on the basis of the WHO Cooperative Project (1989). Tobacco use was assessed during an interview with the patient in accordance with the Order of the Ministry of Health of Ukraine dated 03.08.2012 № 601 «On Approval and Implementation of Medical-Technological Documents on Standardization of Medical Aid in the Termination of the Use of Tobacco Products».

All patients and controls were provided with a complex of clinical and laboratory and instrumental research. A general clinical examination included: a complete physical 
examination, a determination of the severity of psoriasis, an articular examination. Laboratory research included determination of lipid, purine and high-sensitivity CRP indices.

In order to determine the state of the vascular wall, a duplex ultrasonic scan of carotid arteries (CA) was performed for all patients. According to the recommendations of the European Society of Cardiology, scanning of the CA was carried out in three planes - two longitudinal (front and rear) and one transverse. the thickness of the intima-media complex (IMT) was evaluated in the zone of maximal thickening in the orientation of the scanning plane of the longitudinal axis of the vessel. It was calculated the average value of the IMT of the right and left general CA as the mean of 9 measurements in 3 positions; the diagnostic criterion for thickening IMT was considered to be $\geq 0,9$ $\mathrm{mm}$, the presence of an atherosclerotic plaque, with a local thickening of IMT of $>1,5 \mathrm{~mm}$ and more, or a thickening of more than $50 \%$ or $0,5 \mathrm{~mm}$ relative to other areas of IMT.

The mathematical processing of the results was carried out in the IBM SPSS 20 and Statistica 6.0 programs, according to the GCP prior to the data processing. The results base and data preparation for mathematical processing were performed in MS Excel 2007.

This study was approved by the ethics committee of the Shupyk National Medical Academy of Postgraduate Education, Kyiv, Ukraine. All procedures were carried out in accordance with the ethical standards of the responsible committee on human experimentation and with the Helsinki Declaration of 1975, as revised in 2000.

\section{RESULTS}

The average age of patients with PsA was 39,62 $\pm 5,8$ years (20 (46,61\%) women and $22(52,38 \%)$ men), patients with
PS (comparison group) 32,3 $\pm 5,63$ years ( 8 (40\%) women and $12(60 \%)$ men respectively), the control group included 11 women (55\%) and 9 men (45\%), mean age $32,3 \pm 5,63$, respectively. Duration of PsA varied from 3 to 20 years. (Table I).

According to the results of the initial survey, the frequency of the detection of traditional and behavioral risk factors for CVD (smoking, alcohol abuse, sedentary lifestyle) in the PsA group was not significantly different from the group of patients with skin lesions and the control group. The frequency of combination of risk factors for CVD in patients with PsA is given in Table II.

According to the results of the analysis of lipid metabolism, a significant difference was observed between the mean levels of TCin the group of patients with PsA (Table II) compared with the control group. The median levels of TC, TG, LDL cholesterol, VLDL cholesterol were significantly higher in patients with PsA, and HDL cholesterol levels were significantly lower than those in the PS and control groups $(\mathrm{p}<0.05)$.

The increase in the levels of high-sensitivity CRP and UA in the group of patients with PsA was noted in 78,82\% (18 persons) and $21,73 \%$ (5 persons) respectively (Table II).

As can be seen from the data presented in Table II, the frequency of combining behavioral CVD risk factors was not different in the examined groups of patients (PsA and PS) compared with the control group. At the same time, in the group of patients with PsA and PS, dyslipidemia was found to be significantly more frequent in $83,3 \%$ of PsA and $62,5 \%$ of PS and $15 \%$ of control group respectively $(p<0,05)$.

According to the results of the survey, the risk of fatal cardiovascular events in the SCORE scale was determined (Table II), the mean score of the study group was 3,11 $\pm 0,33$.

An increase in the number of FG in blood serum $>4 \mathrm{~g} / \mathrm{l}$ was observed in $11(21,87 \%)$ patients, with an average serum FG level of $4,2 \pm 0,2 \mathrm{~g} / \mathrm{l}$. It was also found that

Table I. The main clinical and demographic characteristics of the examined patients.

\begin{tabular}{|c|c|c|c|}
\hline Indicator & $\begin{array}{c}\text { PsA } \\
n=42\end{array}$ & $\begin{array}{c}\text { PS } \\
\text { without PsA } \\
n=20\end{array}$ & $\begin{array}{c}\text { Control } \\
\text { group } \\
n=20\end{array}$ \\
\hline Age, years & $39,62 \pm 4,80$ & $32,3 \pm 5,63$ & $30,75 \pm 2,13$ \\
\hline Women,(n/\%) & $20(46,61 \%)$ & $8(40 \%)$ & $11(55 \%)$ \\
\hline Men,(n/\%) & $22(52,38 \%)$ & $12(60 \%)$ & $9(45 \%)$ \\
\hline Average duration of the disease & $10,42 \pm 0,34^{*}$ & $4,1 \pm 0,57$ & - \\
\hline DAS 28, points & & - & - \\
\hline Remission $<2,6$ & $4(8,50 \%)$ & - & - \\
\hline Low activity level $\geq 2,6<3,2$ & $9(21,42 \%)$ & - & - \\
\hline Average degree of activity $\geq 3,2<5,1$ & $22(52,38 \%)$ & - & - \\
\hline High degree of activity $\geq 5,1$ & $7(16,66 \%)$ & - & - \\
\hline PASI, points & $14,36 \pm 1,12^{*}$ & $7,2 \pm 1,05$ & - \\
\hline Low activity level < 10 points $n, \%$ & $8(19,04 \%)$ & 3 & - \\
\hline Average degree of activity $\geq 10<20$ points $n, \%$ & $27(64,28 \%)$ & 13 & - \\
\hline High degree of activity $\geq 20$ points $n, \%$ & $7(16,66 \%)$ & 3 & - \\
\hline
\end{tabular}

Note: * the difference between the groups is significant $p<0,05$. 
Table II. Cardiovascular risk factors and state of the vascular wall in the examined patients.

\begin{tabular}{|c|c|c|c|}
\hline Indicator & $\begin{array}{c}\text { PsA } \\
n=42\end{array}$ & $\begin{array}{l}\text { PS } \\
\text { without PsA } \\
n=20\end{array}$ & $\begin{array}{l}\text { Control } \\
\text { group } \\
n=20\end{array}$ \\
\hline $\begin{array}{l}\text { Smoking (at any time in the last } 10 \text { years), } n, \% \text { of } \\
\text { people }\end{array}$ & $69,04 \%$ (29 of people)* & $52,63 \%$ (10 of people) \# & $40 \%$ (8 of people) \\
\hline Low physical activity, $n, \%$ of people & $45,23 \%$ (19 of people) & $47,3 \%$ (9 of people) & $30 \%$ (6 of people) \\
\hline Adiposity, $n, \%$ of people & $16,66 \%$ (7 особи) & $15,78 \%$ (3 of people) & $5 \%$ (1 of people) \\
\hline Stress,n, $\%$ of people & $92,85 \%$ (39 of people)* & $84,2 \%$ (16 of people) \# & $50 \%$ (10 of people) \\
\hline $\begin{array}{l}\text { The heredity of cardiovascular disease is } \\
\text { encumbered, } \\
n, \% \text { of people }\end{array}$ & $69,04 \%$ (29 of people)* & $42,1 \%$ ( 8 of people) & $40 \%$ (8 of people) \\
\hline Incidence of DLP, \% & $83,3 \%$ (35 of people) $)^{*}$ & $62,5 \%$ (20 of people) & $15 \%$ (3 of people) \\
\hline $\mathrm{TC}, \mathrm{mmol} / \mathrm{I}$ & $5,37 \pm 0,2^{*}$ & $4,17 \pm 0,44$ & $3,2 \pm 0,1$ \\
\hline $\mathrm{TG}, \mathrm{mmol} / \mathrm{I}$ & $2,45 \pm 0,2^{*}$ & $1,52 \pm 0,1 \#$ & $1,32 \pm 0,2$ \\
\hline HDL cholesterol, mmol / I & $1,19 \pm 0,1$ & $0,76 \pm 0,1 \#$ & $1,32 \pm 0,1$ \\
\hline LDL cholesterol, mmol / I & $3,45 \pm 0,8^{*}$ & $2,43 \pm 0,3 \#$ & $3,12 \pm 0,3$ \\
\hline VLDL cholesterol, mmol / I & $0,81 \pm 0,4^{*} \#$ & $0,5 \pm 0,1 \#$ & $0,62 \pm 0,1$ \\
\hline Index of atherogenicity, c.u. & $3,69 \pm 0,9^{*} \#$ & $2,47 \pm 0,2 \#$ & $2,7 \pm 0,2$ \\
\hline $\mathrm{CRP},(\mathrm{mg} / \mathrm{l})$ & $8,5 \pm 1,79 * \#$ & $4,45 \pm 0,53 \#$ & $0,77 \pm 0,2$ \\
\hline $\mathrm{UA}(\mathrm{mmmol} / \mathrm{l})$ & $402,85 \pm 15,24^{*} \#$ & $326,68 \pm 15,59 \#$ & $187,83 \pm 8,2$ \\
\hline Fibrinogen & $2,94 \pm 1,02$ & $1,97 \pm 0,77 \#$ & $1,9 \pm 0,2$ \\
\hline SCORE & $3,11 \pm 0,33^{*} \#$ & $2,43 \pm 0,11 \#$ & $1,71 \pm 0,11$ \\
\hline$<2$ CVD RF, \% & $13,05 \% *$ & $15,1 \%$ & $14,9 \%$ \\
\hline 3-5 CVD RF, \% & $69,56 \% *$ & $68,1 \%$ & $67,9 \%$ \\
\hline$>5$ CVD RF, $\%$ & $17,39 \% *$ & $16,8 \%$ & $17,2 \%$ \\
\hline Average value IMT CA, mm & $0,93 \pm 0,02 * \#$ & $0,7 \pm 0,01 \#$ & $0,64 \pm 0,02$ \\
\hline $\mathrm{IMT}>0,9, \mathrm{~mm}$ & $45,83 \% * \#$ & $22,58 \%$ & $5 \%$ \\
\hline Number of atherosclerotic plaques $C A$ & $6,25 \%(2$ ociб)* \# & 0 & 0 \\
\hline
\end{tabular}

Note: * the difference between the groups of patients is significant, $p<0,05$,

\# difference with rupture control is reliable, $p<0,05$.

Table III. Level of IL-10 in serum of the examined patients

\begin{tabular}{cc}
\hline Study groups & Blood serum, $\mathbf{M} \pm \mathbf{m}, \mathbf{p g} / \mathbf{m l}$ \\
\hline PsA & $13,33 \pm 1,31^{*}$ \\
\hline PS & $4,76 \pm 1,02^{*}$ \\
\hline Control group & $2,59 \pm 1,02^{*}$
\end{tabular}

Note: * the difference between the groups is significant $p<0,05$.

serum FG level is significantly higher in smokers than in non-smokers $(\mathrm{p}<0,01)$ and is directly related to the duration of smoking $(\mathrm{r}=0,38, \mathrm{p}<0,05)$ (Table II).

Significant differences were found in the content of IL10 in the group of PsA patients with different degrees of activity of the inflammatory process compared with the group of patients with PS and the control group (Table III).

In the comparative analysis of lipid metabolism indexes, it was found that the average levels of TC, TG, and LDL cholesterol in patients with PsA significantly exceeded the corresponding indices in patients with PS and indicators of healthy individuals in the control group. In this correlation analysis, the greatest influence on IMT CA was found on DAS 28, TC, LDL cholesterol, CRP, FG, PASI ( $r=0,54$, $0,68,0,67,0,53,0,52,0,43$ in accordance). In the group of patients with DAS 28 of medium and high activity $(\geq 3.2)$, a strong correlation between the IMT CA and the level of $\mathrm{UA}(\mathrm{r}=0,61)$ was found. The level of HDL cholesterol was associated with a strong feedback with CRP and a median power of reverse linkage with UA levels. There was a direct correlation between the level of FG and CRP and UA in the average strength $(r=0,54,0,48$, respectively). The given analysis in the group of patients with PS revealed: a direct connection of average strength between IMT CA, TC, LDL cholesterol, CRP ( $r=0,37,0,39,0,38$, respectively). The results of the correlation analysis confirm the relationship of inflammation with dyslipidemia, which plays a significant role in the progression of atherosclerotic vascular lesions and the subsequent formation of CVD.

According to the results of ultrasound examination of carotid arteries, it was found that patients with PsA and PS have a greater severity of atherosclerotic process than healthy peers, which is confirmed by the higher average values of 
IMT in the group of patients with PsA $(0,93 \pm 0,02) \mathrm{p}<0.05$ compared with the group control $(0,68 \pm 0,02)$, with IMT $\geq$ 0,9 detected in $45,83 \%$ of patients with PsA, which is proven complementary RF CDV and in $22,58 \%$ of patients with PS, which is significantly higher than the control group indicator (5\%). It should be noted that the presence of atherosclerotic plaques is diagnosed in 6,25\% of patients with PsA.

\section{DISCUSSION}

Psoriatic arthritis is a chronic, progressive systemic use associated with psoriasis, using localization of the reserve process in the tissues of the musculoskeletal system. There is a special interest in the pseudoplastic with the growth of many people with this pathology and important disabling consequences [23].

The answer to modern beliefs is known as the systemic autoimmune use of a multifactorial nature. At the same time consider what they usually do, as well as humoral immunity. In PSA, as with other spondyloarthritis, they alter the balance of pro- and anti-inflammatory cytokines, which regulate the regulatory measure and participate in the pathogenetic structures of this type of art [5]. The expression of cytokines-regulators of inflammation (interleukin (IL) -1, IL-8, necrosis factor-stimulating alpha (TNF-a), regulators of T-appropriate (IL-2, IL-10, IL-12), regulator B- close immune response (IL-4, IL-6, IL-16), and even weaker good good cytokines - IL-17, IL-20, etc. [24].

In this regard, there is a need for a more detailed study of cardiovascular risk factors for IL-10 in patients with psoriatic arthritis and their impact on CVD, in addition to the development of atherosclerotic lesions, which was the purpose of our study.

According to the results of our study, the prevalence of CVD behavioral risk factors and their combinations does not differ in the groups of patients with PSA, PS and the control group. Dyslipidemia is more common in patients with PsA than in patients with psoriasis $(\mathrm{p}<0,05)$ and in the control group, which is manifested by increased levels of TC, LDL cholesterol and lowering of HDL cholesterol in patients with PsA compared to other subjects. In the development of the atherosclerotic process in patients with PsA, the pro-traditional risk factors play an important role as the immune-inflammatory factors (CRP, IL-10) and additional risk factors (UA).

\section{CONCLUSIONS}

1.The prevalence of behavioral risk factors for CVD and their combinations is not different in the groups of patients with PsA, PS and control group.

2. Dyslipidemia is more common in patients with PsA than in patients with psoriasis $(\mathrm{p}<0,05)$ and in the control group, which is manifested by increased levels of TC, LDL cholesterol and lowering of HDL cholesterol in patients with PsA compared to other subjects.

3. For patients with PsA, a greater severity of atherosclerotic vascular lesions is observed in comparison to patients with psoriatic skin disease and healthy persons, which is confirmed by the mean value of IMT $\geq 0,9$ mmfound at
$45.83 \%(\mathrm{p}<0,05)$, whereas $\mathrm{AB}$ was found at $6,25 \%(\mathrm{p}<0,05)$. 4.In patients with PsA and PS, there is a significant increase in serum IL-10 level compared to healthy subjects, indicating an increase in the synthesis of this anti-inflammatory cytokine in response to a chronic immune-inflammatory process characteristic to PsA.

5. In the development of the atherosclerotic process in patients with PsA, the pro-traditional risk factors play an important role as the immune-inflammatory factors (CRP, IL-10) and additional risk factors (UA).

\section{REFERENCES}

1. Badokin V.V., Korsakova Yu.L. Terapevticheskaya aktivnost'i ibezopasnost' artrofoona pri psoriaticheskom artrite [Therapeutic activity and safety of artrofone in psoriatic arthritis]. Consilium Medicum. 2006;(8). (Ru)

2. Mastroianni A. at al. Cytokine profiles during infliximab monotherapy in psoriatic arthritis. British Journal of Dermatology.2005; 153(3): 531-536.

3. Gottlieb A.B., Chao C., Dann F. et al. Psoriasis comorbidities. Journal of Dermatological Treatment. 2008; 19 (1):5-21.

4. Milosavljevic J., Lindqvist U., Elvin A. et al. Ultrasound and Power Doppler Evaluation of the Hand and Wrist in Patients with Psoriatic Arthritis. Acta Radiologica. 2005; 46 (4):374-385.

5. Gottlieb A. et al. Guidelines of care for the management of psoriasis and psoriatic arthritis: Section 2. Psoriatic arthritis: overview and guidelines of care for treatment with an emphasis on the biologics. Journal of the American Academy of Dermatology. 2008; 58(5): 851- 864.

6. Gottlieb A. et al. Guidelines of care for the management of psoriasis and psoriatic arthritis: Section 2. Psoriatic arthritis: overview and guidelines of care for treatment with an emphasis on the biologics. Journal of the American Academy of Dermatology. 2008; 58(5): 851- 864.

7. Ellis C.N. Effects of alefacept on health-related quality of life in patients with psoriasis results from a randomized, placebo-controlled phase II trial. American Journal of Clinical Dermatology.2003; 4 (2): 131-139.

8. Stefano I., Eugenio R., Antonio R. Echographic test and cyclosporin therapy in psoriatic arthritis. Journal of the European Academy of Dermatology and Venereology. 2000; 14 (3): 232-233.

9. Kochergin N.G., Kochergin S.N., Smirnova L.M. Itogi raboty' Pervoj vsemirnoj konferencii po psoriazu i psoriaticheskomu artritu. [Results of first international conference of psoriasis and psoriatic arthritis]. Russkij medicinskij zhurnal. 2006. (Ru)

10. Cohen A.D. et al. Psoriasis and diabetes: a population-based crosssectional study. Journal of the European Academy of Dermatology and Venereology. 2008; 22(5): 585-589.

11. Titov V.N., Boytsov S.A., Urazalinaet S.F. al. Vzaimosvyaz mochevoy kisloty s pokazatelyamya lipidnogo obmena u lits s nizkim i srednim riskom po shkale SCORE [Interconnection of uric acid and indexes of lipid metabolism in patients with medium risk, according to SCORE scale]. Ateroskleroz i dislipidemii. 2013; 2: 31-39. (Ru)

12. Chandran V., Schentag C.T., Gladman D.D. et al. Sensitivity and specificity of the caspar criteria for psoriatic arthritis in a family medicine clinic setting. The Journal of Rheumatology. 2008; 35(10): 2069-2070.

13. Mitchenko 0.I., Lutay M.I. et al. Dislipidemiï: diagnostika, profilaktika ta likuvannya. Metodichni rekomendatsiï asotsiatsiï kardiologiv Ukraïni [Dislipidemia: diagnostics, prophylaxis, and treatment. Methodical recommendations of Cardiologists association of Ukraine]. Kiev. Morion. 2011. Available from: http://strazhesko.org.ua/upload/2014/02/20/ guidelines_dyslipid_2011_new.pdf (UA) 
14. Kovalenko V.M., Khimion L.V., Lysenkoetal G.I. Vpliv imunnogo status i lipidnix-faktoriv na progresuvannya subklinichnogo aterosklerozu i rozvitok sercevo-sudinnix zaxvoryuvan u paciyentiv iz revmatoidnim artritom [Influence of immune status and lipid factors on progress of subclinical atherosclerosis treatment and development of cardio-vascular diseases in patients with rheumatoid arthritis]. Ukrainian Rheumatology Journal. 2011; 43 (1). Available from: http://www.rheumatology. kiev.ua/article/940/vpliv-imunnogo-statusu-i-lipidnix-faktoriv-naprogresuvannya-subklinichnogo-aterosklerozu-i-rozvitok-sercevosudinnix-zaxvoryuvan-u-paciyentiv-iz-revmatoidnim-artritom . (UA)

15. Gonzalez-Juanatey C., Llorca J., Amigo-Diaz E. et al. High prevalence of subclinical atherosclerosis in psoriatic arthritis patients without clinically evident cardiovascular disease or classic atherosclerosis risk factors. ArthritisRheum.2007; 57(6):1074-1080.

16. Franse L.V., Pahor M., Di Bari M. et al. Serum uric acid, diuretic treatment and risk of cardiovascular events in the Systolic Hypertension in the Elderly Program (SHEP) J. Hypertens. 2000;18: 1149-1154.

17. Grayson P.C., Kim S.Y., LaValley M. et al. Hyperuricemia and incident hypertension: a systematic review and meta-analysis. Arthritis Care Res (Hoboken). 2011; 63(1): 102-110.

18. Keenan T., Blaha M.J., Nasir K. et al. Relation of uric acid to serum levels of high-sensitivity C-reactive protein, triglycerides, and high-density lipoprotein cholesterol and to hepatic steatosis. Am J Cardiol. 2012; 110(12): 1787-1792.

19. Susan G. Lakoski, Yongmei Liu, K. Bridget Brosnihan, et al. Interleukin-10 concentration and coronary heart disease (CHD) event risk in the estrogen replacement and atherosclerosis (ERA) study. Atherosclerosis.2008; 197 (1): 443-447.

20. Giuseppina Caligiuri, Mats Rudling, Véronique Ollivier, et al. Interleukin-10 Deficiency Increases Atherosclerosis, Thrombosis, and Low-density Lipoproteins in Apolipoprotein E Knockout Mice.Molecular Medicine. 2003; 9:10-17.

21. Mälarstig A., Eriksson P., Hamsten A., et al. Raised interleukin-10 is an indicator of poor outcome and enhanced systemic inflammation in patients with acute coronary syndrome. Heart.2008; 94:724-729.
22. Christopher Heeschen, Stefanie Dimmeler, Christian W. Hamm, et al. Serum Level of the Antiinflammatory Cytokine Interleukin-10 Is an Important Prognostic Determinant in Patients With Acute Coronary Syndromes.2003;107:2109-2114.

23. Mease P., Goffe B.S. Diagnosis and treatment of psoriatic arthritis. J Am Acad Dermatol. 2005; 52(9): 1-19.

24. Mastroianni A. Cytokine profiles during infliximab monotherapy in psoriatic arthritis. British Journal of Dermatology. 2005; 153(16): 531-536.

The work is a fragment of the research project of the Department of Family Medicine of the Shupyk National Medical Academy of Postgraduate Education «Scientific and medical support for standardization and personalization of medical, preventive and rehabilitation activities of general practitioners - family doctor» (State Registration No. 0118U001145).

\section{ORCID and contributionship:}

Liudmyla V. Khimion - 0000-0001-7699-8725 A,E,F

Alina V. Boiko - 0000-0003-4656-1236 A,B,C,D

\section{Conflict of interest:}

The Authors declare no conflict of interest

\section{CORRESPONDING AUTHOR Alina V. Boiko \\ Department of Family Medicine of the \\ Shupyk National Medical Academy of Postgraduate Education. \\ 9 Dorogozhytska str, Kyiv, Ukraine \\ tel: +380683888776 \\ e-mail:alina181290@gmail.com}

Received: 23.01 .2020

Accepted: 01.04 .2020

A - Work concept and design, B - Data collection and analysis, C - Responsibility for statistical analysis,

D -Writing the article, $\mathbf{E}$ - Critical review, $\mathbf{F}$ - Final approval of the article 